\title{
First Report on Chronic Effects of Non-Microcystin Producing Cyanobacteria, Cylindrospermopsis \\ Curvispora and Planktothrix sp., on Daphnia Magna
}

\author{
Thanh-Son Dao (Corresponding author) \\ Hochiminh City University of Technology, 268 Ly Thuong Kiet Street \\ District 10, Hochiminh City, Vietnam \\ Tel: 84-838-639-682Ｅ-mail: dao.son@hcmut.edu.vn \\ Thi-My-Chi Vo \\ Hochiminh City University of Technology, 268 Ly Thuong Kiet Street \\ District 10, Hochiminh City, Vietnam \\ Tel: 84-838-639-682Ｅ-mail: vtmchi@hcmut.edu.vn
}

\begin{abstract}
Thanh-Luu Pham
Institute of Tropical Biology, Vietnam Academy of Science and Technology (VAST)

85 Tran Quoc Toan Street, District 3, Hochiminh City. Vietnam

Tel: 84-961-291-688Ｅ-mail: thanhluupham@gmail.com
\end{abstract}

Received: June 28, 2016 Accepted: August 19, 2016

doi:10.5296/emsd.v5i2.9867

URL: http://dx.doi.org/10.5296/emsd.v5i2.9867

\begin{abstract}
Cyanobacteria are an essential part of aquatic ecosystems. However, they can cause detrimental impacts on other organisms of higher tropic levels in water bodies because of their potent toxic metabolites (e.g. microcystin) and other bioactive compounds. In this study we tested the long-term and negative effects of two non-microcystin producing cyanobacteria Cylindrospermopsis curvispora and Planktothrix sp. from Vietnam on Daphnia magna under the laboratory conditions. The animal was fed with mixtures of green alga, Scenedesmus sp., and C. curvispora or Planktothrix sp. at different ratios (100\% Scenedesmus, $10 \%$
\end{abstract}


cyanobacteria $+90 \%$ Scenedesmus, $50 \%$ cyanobacteria $+50 \%$ Scenedesmus, $100 \%$ cyanobacteria) over a period of 21 days. The results showed that the $D$. magna fed with from 10 to $100 \%$ cyanobacteria reduced their survival with density dependence, delayed or postponed its maturation. Besides, the cyanobacteria also inhibited the reproduction of adult D. magna consequently strongly prevent the next population development of D. magna. The species $C$. curvispora had stronger effect on survival, but less impact on maturation and reproduction of D. magna than Planktothrix sp, negatively. To our knowledge, this is the first report on negative effects of $C$. curvispora and Planktothrix sp. from Vietnam on life history traits of D. magna. Additionally, our results revealed that even non-microcystin producing cyanobacteria at low density could also have negative impacts on zooplankton consequently ecological balance interference. In situ investigations on the effects of cyanobacteria on zooplankton are suggested for more understanding on the ecological interactions of the two trophic levels of aquatic ecosystem.

Keywords: Negative effects, Daphnia magna, Cylindrospermopsis curvispora, Planktothrix sp.

\section{Introduction}

A century of eutrophication has resulted in a worldwide increase of cyanobacterial abundance in lakes (Hallegraeff 1993). Many studies showed that cyanobacteria negatively affect zooplankton, even if they do not produce toxins. Cyanobacterial exposure can cause severe impairment on life history traits of daphnids (Porter 1980). Hietala et al. (1997) fed Daphnia pulex with toxic Microcystis and observed the mortality intensification in the exposures. Investigation of Rorhlack et al. (2005) indicated that Planktothrix produced compound inhibiting the trypsin activity of D. magna. Besides, non-toxic Cylindrospermopsis raciborskii caused abortion of Daphnia pulicaria (Bednarska and Slusarczyk 2013). Daphnia magna fed with toxic Microcystis decreased its dry mass and the effect was density dependent (Trubetskova and Haney 2006). Mother Daphnia exposed to the cyanobacterial toxin, microcysin-LR, induced a decrease of dry mass of its offspring even though the offspring were raised in non-toxic medium (Ortiz-Rodriguez et al. 2012). Beside effects on survival or reproduction, DeMott (1999) also showed an inhibition on feeding rate when he conducted experiments of five Daphnia species exposed to mixtures of green alga, Scenedesmus, and cyanobacterium, Microcystis, for 7 days.

Guo and Xie (2006) hypothesized the tolerance development against toxic M. aeruginosa in Daphnia carinata, Ceriodaphnia cornuta, Moina micriura after exposing the 3 daphnid species to mixture of Scenedesmus and Microcystis trans-generationally for 4 weeks. The results clearly showed the development of tolerance in $C$. cornuta and $M$. micriura but $D$. carinata, to toxic Microcystis. Similarly, Gustafsson and Hansson (2004) and Gustafsson et al. (2005) reported that Daphnia pre-exposed of toxic Microcystis had lower mortality and growth faster than Daphnia in control indicating maternal effect to Daphnia under exposure to toxic Microcystis.

Nowadays, the nutrient value of non-toxic cyanobacterial to zooplankton has been a matter of controversy. While many studies has showed that non-toxic cyanobacteria are a poor quality 


\section{Macrothink}

food for zooplankton (Porter 1980, Infante and Abella 1985, Hazanato and Yasuno 1987, Matveev and Balseiro 1990, Lundstedt and Brett 1991, Smith and Gilbert 1995), other studies have shown that some species of zooplankton exhibited good survival and growth when fed on cyanobacteria (Burns and Xu 1990, Gliwicz 1990, Fulton and Jones 1991). Over all, toxicity of cyanobacteria to Daphnia has been studied mainly with the toxic and non-toxic species of M. aeruginosa, Planktothrix agardhii and C. raciborskii. However, toxicity of the species Cylindrospermopsis curvispora to zooplankton has not been known and there have been few studies of the negative effects of non-microcystin producing filamentous cyanobacteria Planktothrix on micro-crustaceans. Therefore, in this study, we investigate adverse effects of two non-microcystin producing cyanobacteria $C$. curvispora and Planktothrix sp. isolated from Vietnam on D. magna.

\section{Materials and Methods}

\subsection{The Test Organisms}

Daphnia magna Straus was purchased from the MicroBioTests Inc, Belgium. The animal has been fed with green alga Scenedesmus sp. and maintained in the laboratory conditions of $22 \pm$ $1{ }^{\circ} \mathrm{C}$, dim light and light dark cycle of $14 \mathrm{~h}$ light: $10 \mathrm{~h}$ dark. Two cyanobacterial strains, Cylindrospermopsis curvispora and Planktothrix sp., were used for exposure to D. magna (Fig. 1). The cyanobacterium C. curvispora was isolated from a small pond in District 7 , Hochiminh City, during its mass development, while the other species, Planktothrix sp. was isolated from Dau Tieng Reservoir, Tay Ninh Province, Vietnam. Both cyanobacterial strains were cultivated in Z8 medium (Kotai 1972) with continuous aeration and under the laboratory conditions of $25 \pm 1{ }^{\circ} \mathrm{C}$, light intensity of around $3000 \mathrm{Lux}$, and light dark cycle of 12h light: $12 \mathrm{~h}$ dark.
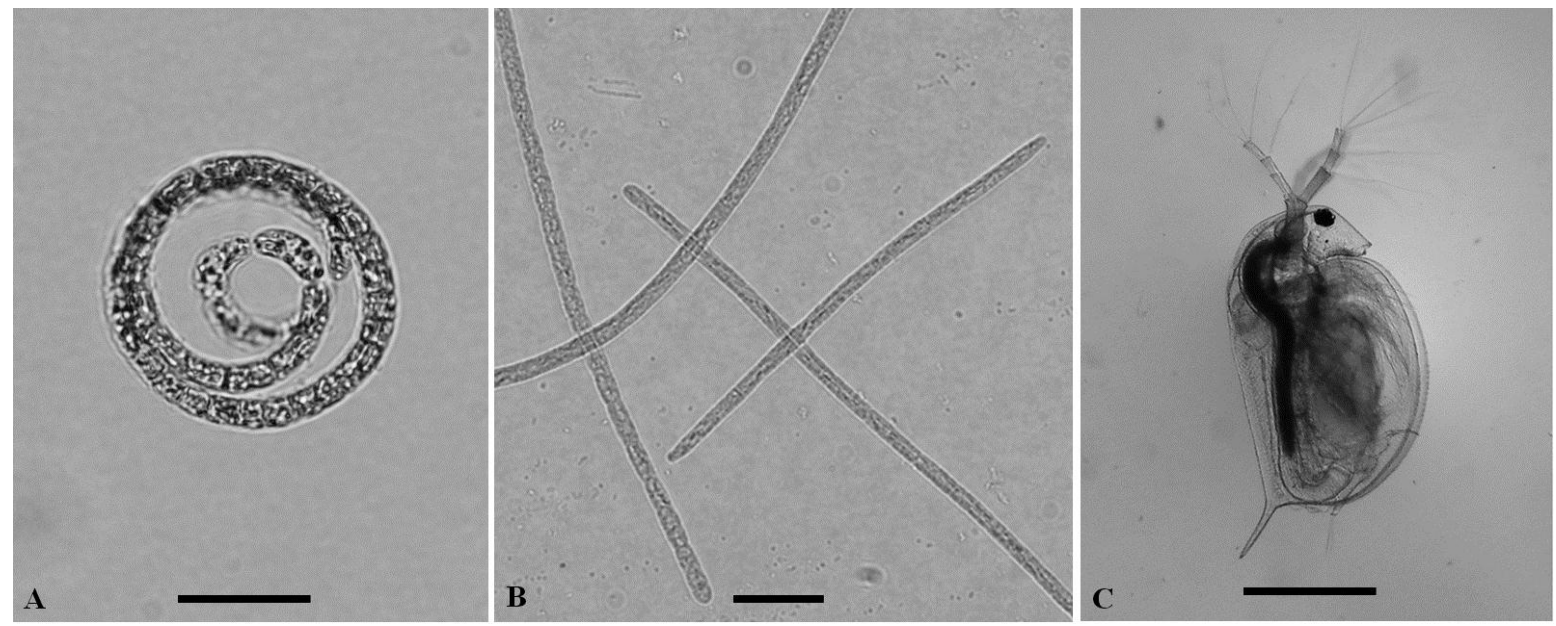

Figure 1. The organisms for the toxicity test. A, Cylindrosmeropsis curvispora; B,

Planktothrix sp.; C: newly born Daphnia magna. Scale bars of A and B $=20 \mu \mathrm{m}$; scale bar of

$$
\mathrm{C}=300 \mu \mathrm{m}
$$

\subsection{Toxin Analysis}

Both cyanobacterial isolates were used for microcystins (MCs) characterization. Each 
cyanobacterial culture was harvested during the exponential growth phase and filtered onto GF/A filters (Fiore, France), dried at $50{ }^{\circ} \mathrm{C}$ over night and stored at $-70{ }^{\circ} \mathrm{C}$ prior to toxin determination. For MCs determination, the filters containing microbes were cut into small pieces with scissors. Extraction of MCs was conducted according to Pham et al. (2015). Briefly MCs were firstly extracted in $5 \mathrm{~mL}$ of $100 \%$ (vol/vol) aqueous methanol by shaken for $60 \mathrm{~min}$ followed by $2 \times 60 \mathrm{~min}$ of extraction in $3 \mathrm{~mL}$ of $75 \%$ aqueous methanol. Each extraction step was followed by centrifugation (4 $500 \mathrm{rpm}, 30 \mathrm{~min}, 4^{\circ} \mathrm{C}$ ). The supernatants of all extractions from each sample were pooled, dried at room temperature, re-dissolved in 0.5 $\mathrm{mL} \mathrm{MeOH} \mathrm{(100 \% )} \mathrm{and} \mathrm{centrifuged} \mathrm{at} 8.000 \mathrm{rpm}, 4{ }^{\circ} \mathrm{C}$ for 5 minutes. The supernatant was passed through a Minisart RC 4 filter membrane $(0.2 \mu \mathrm{m}$ pore size, Sartorius, Germany) prior to HPLC analysis. The HPLC (Shimadzu, Japan) equipped with a silica based reverse phase $\mathrm{C}_{18}$ column (Waters SunFire ${ }^{\mathrm{TM}}$, Ireland), maintained at $40{ }^{\circ} \mathrm{C}$. A $0.05 \mathrm{M}$ phosphate buffer (pH 2.5) in $\mathrm{MeOH}(50 / 50, \mathrm{v} / \mathrm{v})$ was used as mobile phase, at a flow rate of $0.58 \mathrm{~mL} / \mathrm{min}$. MCs congeners were detected by the UV detection at $238 \mathrm{~nm}$ with a photodiode UV-visible array detector. Microcystin-LR, -RR and -YR purchased from Wako chemicals company (Osaka, Japan) were used as standards. The HPLC system had a detection limit of $0.01 \mu \mathrm{g} / \mathrm{L}$.

\subsection{Toxicity Test}

Fifteen neonates $(<24 \mathrm{~h}$ old) were used for each chronic experiment (Adema 1978) and individually raised in $50 \mathrm{~mL}$ beakers containing $20 \mathrm{~mL}$ of medium (Dao et al. 2010). In the control experiment, the Daphnia was fed with $100 \%$ of green alga Scenedesmus sp. In exposures, Daphnia was fed with a mixture of Scenedesmus and cyanobacteria (either $C$. curvispora or Planktothrix sp.) with total concentration of $1 \mathrm{mg} \mathrm{C/L/day} \mathrm{(Gustafsson} \mathrm{et} \mathrm{al.}$ 2005) at three different regimes (1) $10 \%$ Scenedesmus + $90 \%$ cyanobacteria; (2) $50 \%$ Scenedesmus + $50 \%$ cyanobacteria; and (3) $100 \%$ cyanobacteria (Table 1). In total, seven incubations including one control and six different exposures were conducted. All medium and food were renewed every two days. The life history traits of Daphnia such as survival, maturity age, reproduction were daily observed. The incubations lasted for 21 days.

Table 1 . Summary of the treatments in the toxicity test.

\begin{tabular}{|c|c|c|c|c|}
\hline \multirow{2}{*}{ No. } & \multirow{2}{*}{ Treatments } & \multicolumn{3}{|c|}{ Biomass proportion of food (green alga and cyanobacteria) } \\
\cline { 3 - 5 } & & Scenedesmus sp. & Cylindropsermopsis curvispora & Planktothrix sp. \\
\hline 1 & Control & $100 \%$ & $0 \%$ & $0 \%$ \\
\hline 2 & $10 \% \mathrm{Cc}$ & $90 \%$ & $10 \%$ & $0 \%$ \\
\hline 3 & $50 \% \mathrm{Cc}$ & $50 \%$ & $50 \%$ & $0 \%$ \\
\hline 4 & $100 \% \mathrm{Cc}$ & $0 \%$ & $100 \%$ & $0 \%$ \\
\hline 5 & $10 \% \mathrm{Pl}$ & $90 \%$ & $0 \%$ & $10 \%$ \\
\hline 6 & $50 \% \mathrm{Pl}$ & $50 \%$ & $0 \%$ & $50 \%$ \\
\hline 7 & $100 \% \mathrm{Pl}$ & $0 \%$ & $0 \%$ & $100 \%$ \\
\hline
\end{tabular}

\subsection{Statistical Analysis}

Sigmaplot version 12 was used for the data treatment. Kruskal-Wallis test was applied for calculation on statistically significant difference of the maturation of D. magna. 


\section{Macrothink \\ Environmental Management and Sustainable Development \\ ISSN 2164-7682 2016, Vol. 5, No. 2}

\section{Results}

\subsection{Effects of Cyanobacteria on the Survivorship of Daphnia magna}

The toxin analysis showed that both cyanobacterial species, C. curvispora and Planktothrix sp., did not produce MCs. Therefore, the used cyanobacterial strains for Daphnia experiments could be considered as non-MCs producing cyanobacterial strains.

In control, all D. magna were well alive by the end of experiment. On the other hand, Daphnia started to die after 2 weeks of incubation in $10 \% \mathrm{Cc}$ but it did within the first week in $50 \% \mathrm{Cc}$ and $100 \% \mathrm{Cc}$. By the end of incubation, the Daphnia exposed to $10 \%, 50 \%$ and $100 \% \mathrm{Cc}$ reduced their survival by $33 \%, 60 \%$ and $67 \%$, respectively (Fig. 2a). Exposure to $10 \%$ and $50 \% \mathrm{Pl}$ caused a reduction of $20 \%$ of Daphnia population after 3 weeks of incubation. Besides, $47 \%$ of population of Daphnia died after 3 weeks feeding on Planktothrix sorely (Fig. 2b). Mortality of Daphnia occurred after $4-5$ days of exposure in all three Planktothrix treatments. The higher concentration of cyanobacteria the animals exposed the lower survival they had.

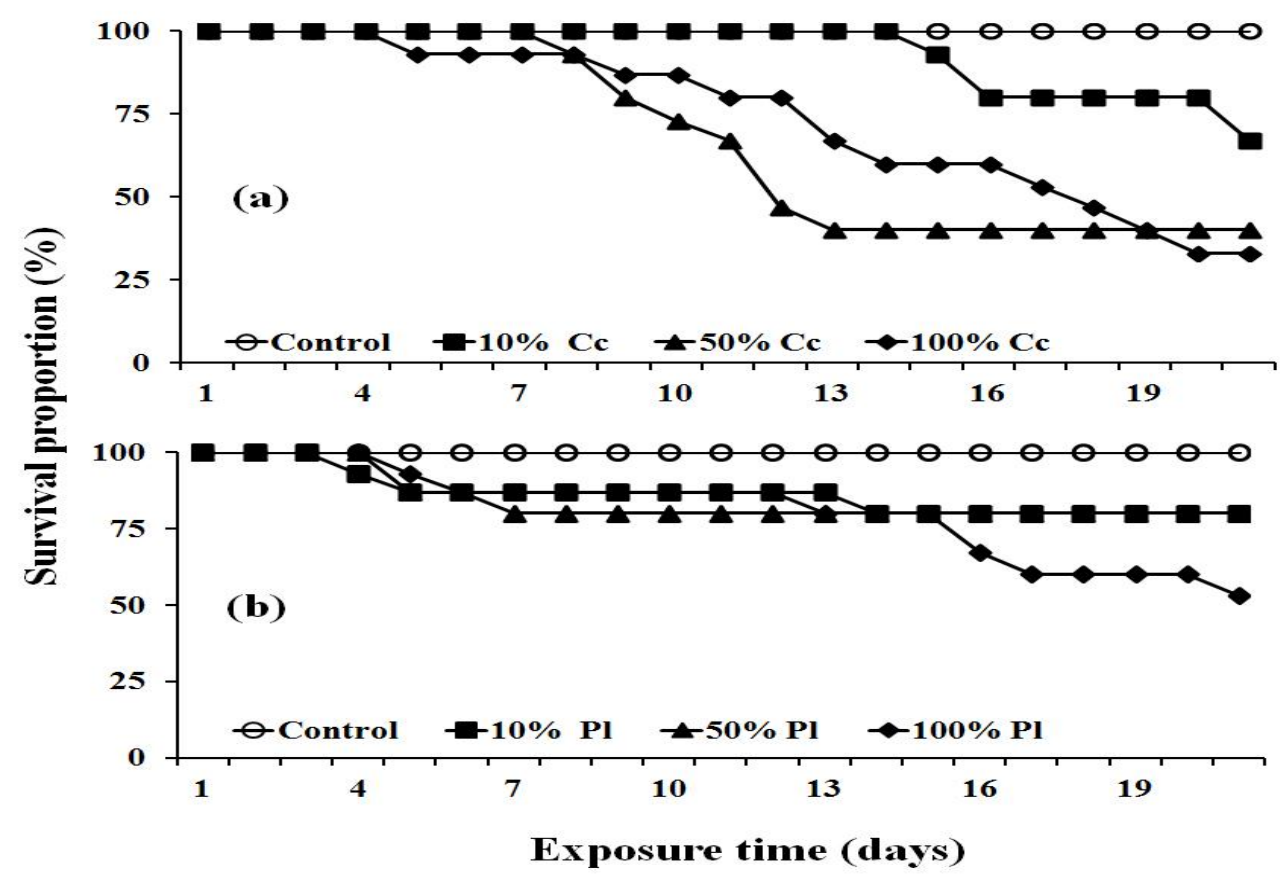

Figure 2. Survival of Daphnia magna from control and exposures during 3 weeks of incubation. Abbreviation as in Table 1

\subsection{Effects of Cyanobacteria on the Maturation of Daphnia Magna}

Daphnia raised in control reached its maturity at the age of around 6 days old. However, the animals exposed to cyanobacterial isolates delayed their maturation, from 7.5 - 9 days old (Fig. 3). Seriously, those in the treatment of $100 \% \mathrm{Pl}$ were not able to reach their maturation (Fig. 3) although 53\% of the population was alive till the last day of experiment (Fig. 2b). 


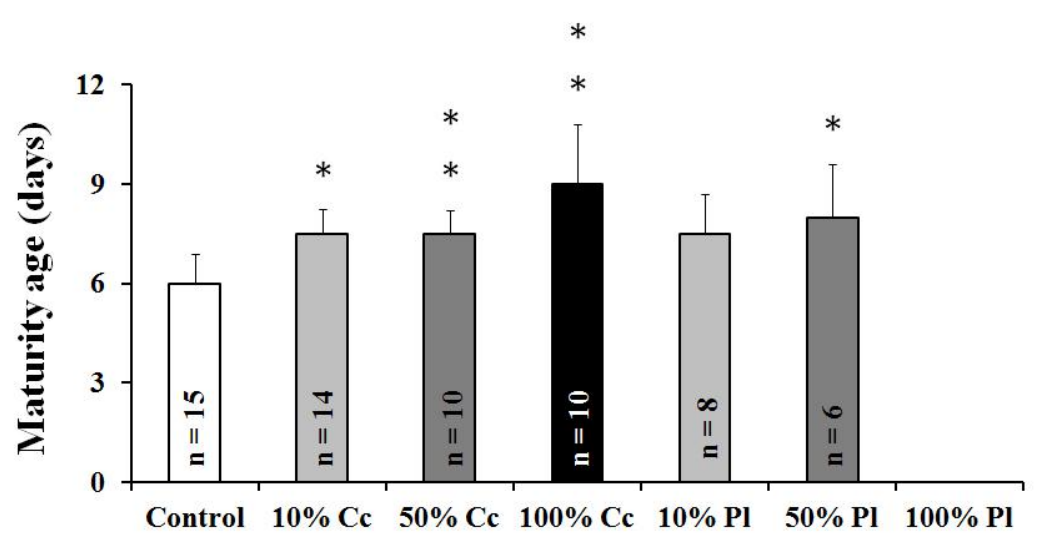

Exposures

Figure 3. Maturation of Daphnia magna (mean value $\pm \mathrm{SD}$ of $\mathrm{n}$ as indicated in the columns) from control and exposures during 3 weeks of incubation. Asterisks indicate significant difference by Kruskal-Wallis test $\left(^{*}, \mathrm{p}<0.01\right.$; $\left.^{*}, \mathrm{p}<0.001\right)$. Abbreviations as in Table 1 .

\subsection{Effects of Cyanobacteria on the Reproduction of Daphnia magna}

The first offspring of Daphnia were observed at the ninth day in the control and Cylindrospermopsis incubations (Fig. 4a, b). However, they were recorded earlier in $10 \% \mathrm{Pl}$ treatment, after 7 days of treatment (Fig. 4c). The number of offspring in control was linear in increase during the experiment. Nevertheless, it was slowly increased in the cyanobacterial exposures (Fig. 4). The accumulative neonates in control was 479, much higher than those in the cyanobacterial exposures, 123 neonates from $10 \% \mathrm{Cc}, 37$ from $50 \% \mathrm{Cc}, 34$ from $100 \%$ Cc, 3 from $10 \% \mathrm{Pl}$, and 19 from $50 \% \mathrm{Pl}$. No neonate was obtained from $100 \% \mathrm{Pl}$ treatment (Table 2). 


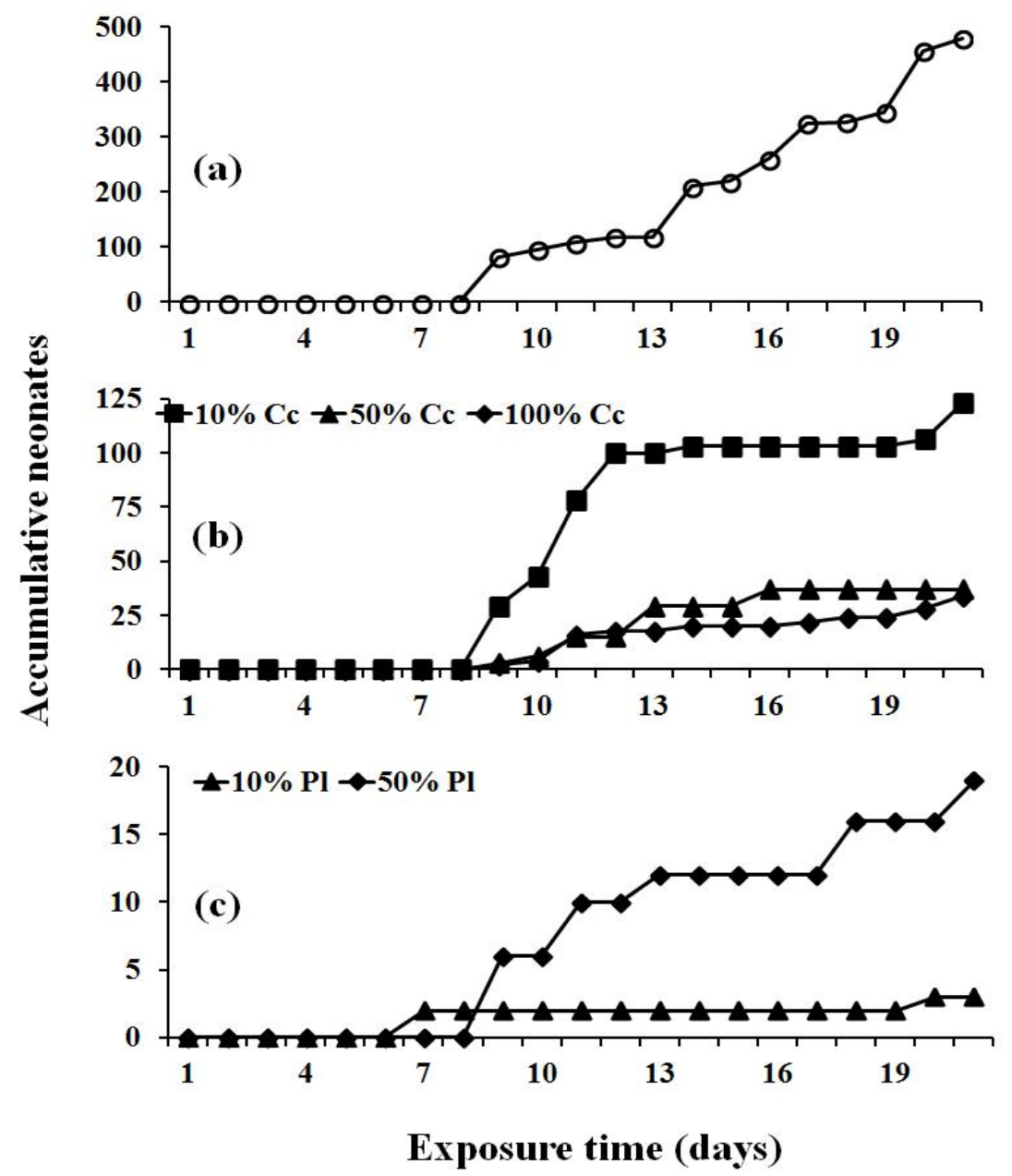

Figure 4. Reproduction of mother D. magna during control incubation (a), Cylindrospermopsis treatment (b) and Planktothrix exposure (c). Abbreviation as in Table 1.

Table 2: Accumulative neonates of D. magna after three weeks of incubation. Abbreviation as in Table 1.

\begin{tabular}{|c|c|c|c|c|c|c|c|}
\hline & Control & $10 \% \mathrm{Cc}$ & $50 \% \mathrm{Cc}$ & $100 \% \mathrm{Cc}$ & $10 \% \mathrm{Pl}$ & $50 \% \mathrm{Pl}$ & $100 \% \mathrm{Pl}$ \\
\hline Accumulative neonates & 479 & 123 & 37 & 34 & 3 & 19 & 0 \\
\hline
\end{tabular}

\section{Discussion}

As the live cells of cyanobacteria ( $C$. curvispora and Planktothrix sp.) and green alga (Scenedesmus) were added into the medium as food, the physical characteristics of the test medium (e.g. pH, alkalinity, hardness) after food addition might be slightly changed and should result in similar physical characteristics, biologically. Besides, the secondary metabolites in cyanobacteria (e.g. microcystin, bioactive compounds) are cell-bound substances. Therefore, the observed effects on D. magna in the exposures should be induced by the cyanobacterial isolates used as food in our experiment. 


\section{MInstitute Machink $_{\text {inth }}$}

The mortality of exposed D. magna in our study was in agreement with the investigation of Da Costa et al. (2013), in which non-toxic C. raciborskii reduced the survival of D. pulex, $M$. micrura during 12 - 15 experimental days. Oberhaus et al. (2007) reported that no negative effects on Daphnia's survival feeding on toxic P. rubescens and P. agardhii. Hence the cyanobacterium Planktothrix sp. in the current study showed apparent toxicity to Daphnia which could be explained as different species or strains of cyanobacteria would have different toxic capacity and toxin production (Cronberg and Annadotter 2006). Generally, $C$. curvispora had stronger impact on survival of Daphnia than Planktothrix sp. (Fig. 2a, b). The hypothesis is suggested that both of cyanobacterial species may produce some toxic compounds other than MCs, but the concentration of toxic compounds in Cylindrospermopsis was higher than that in Planktothrix sp. This observation may be explained as (i) the used cyanobacterial species for our experiments could produce other toxic bio-active compounds to Daphnia, and (ii) cyanobacteria are low nutritional value (e.g. absence of essential polyunsaturated fatty acid and sterols) for Daphnia which was reported elsewhere (Brett et al. 1997, Von Elert 2002).

Cyanobacteria are not nutrient food for Daphnia's growth while green alga Scenedesmus was used as a good food for the animal. So, the postponement of maturation should be closely related to toxic bio-active compounds from the cyanobacteria at least in the lower cyanobacterial proportion treatments $(10 \%$ and $50 \% \mathrm{Cc}, 10 \%$ and $50 \% \mathrm{Pl})$. We recognized that the body size of the animals exposed to cyanobacteria was smaller than animals in control treatment (data not showed). According to Green (1956) and Ebert (1991), smaller Daphnia would take more instars to mature than larger Daphnia (Green 1956, Ebert 1991). Therefore, the maturation of Daphnia in cyanobacterial treatments delayed compared to control.

Our record on reproduction of D. magna supported the results in a previous investigation (Lürling and Van der Grinten 2003). The same authors showed the negative effects of non-toxic $M$. aeruginosa on body length, reproduction (number of new born per female) and clearance rate of Daphnia. In the natural environment, the effects of cyanobacteria, even non-toxic, on zooplankton can have some implications. For example, it can reduce zooplankton's vitality and growth rate, lead their populations to decline. Therefore, the effect of cyanobacteria on zooplankton can interfere in some ways with decreasing the fitness of these species

\section{Conclusions}

Though non-MCs producers, both C. curvispora and Planktothrix sp. negatively affected life history traits of D. magna, including mortality increase, maturation postponement or inhibition and reproduction reduction. The adverse effects were concentration dependent. The toxicity of $C$. curvispora was more potent than Planktothrix sp. To the best of our knowledge, this is the first information on chronic effects of non-MCs producing cyanobacteria, $C$. curvispora and Planktothrix sp. on D. magna. This study revealed that these cyanobacterial species may product some toxic bio-active compounds other than MC which need further analysis with modern equipment, e.g. LC/MS, GC/MS. Besides, more attention to the 
presence, distribution of cyanobacteria in nature should be paid. Negative impacts of $C$. curvispora and Planktothrix sp. on other aquatic organisms (e.g. aquatic plants, fish, micro-algae) should be investigated to get more understanding on the toxicity of these cyanobacteria on the aquatic ecosystem.

\section{Acknowledgement}

This research is funded by Hochiminh City University of Technology - VNU-HCM and CARE-RESCIF initiative under grant number Tc-MTTN-2016-04, and Vietnam National Foundation for Science and Technology Development (NAFOSTED) under grant number 106-NN.04-2014.69.

\section{References}

Adema, D. M. M. (1978). Daphnia magna as a test animal in acute and chronic toxicity tests. Hydrobiologia, 59, 125-134. DOI: 10.1007/BF00020773.

Bednarska, A., Slusarczyk, M. (2013). Effect of non-toxic, filamentous cyanobacteria on egg abortion in Daphnia under various thermal conditions. Hydrobiolgia, 715, 151-157. DOI: 10.1007/s10750-012-1424-2.

Brett, M. T., Muller-Navarra, D. C. (1997). The role of highly unsaturated fatty acids in aquatic food web processes. Freshwater Biology, 38(3), 483-499. DOI: 10.1046/j.1365-2427.1997.00220.x.

Burns, C. W., Xu, Z. (1990). Calanoid copepods feeding on algae and filamentous cyanobacteria: rates of ingestion, defecation and effects on tricome length. Journal of Plankton Research. 12, 201-213. DOI: 10.1093/plankt/12.1.201.

Cronberg, G., \& Annadotter, H. (2006). Manual on aquatic cyanobacteria - A photo guide and a synopsis of their toxicology. Kerteminde Tryk A/S, 1-106.

Da Costa, S. M., Ferrão-Filho, A. S., Azevedo, S. M. F. O. (2013). Effects of saxitoxin- and non-saxitoxin-producing strains of the cyanobacterium Cylindrospermopsis raciborskii on the fitness of temperate and tropical cladocerans. Harmful Algae, 28, 55-63. DOI: 10.1016/j.hal.2013.05.017.

Dao, T. S., Do-Hong, L. C., Wiegand, C. (2010). Chronic effects of cyanobacterial toxins on Daphnia magna and their offspring. Toxicon, 50, 1244-1254. DOI: 10.1016/j.toxicon.2010.01.014.

DeMott, W. R. (1999). Foraging strategies and growth inhibition in five daphnids feeding on mixtures of a toxic cyanobacterium and a green alga. Freshwater Biol. 42, 263-274. DOI: 10.1046/j.1365-2427.1999.444494.x.

Ebert, D. (1991). The effects of size at birth, maturation, threshold and genetic difference on the life-history of Daphnia magna. Oecologia, 86, 143-250. DOI: 10.1007/BF00317537.

Fulton, R. S., Jones, C. (1991). Growth and reproductive responses of Daphnia to cyanobacterial blooms on the Potomac River. Internationale Revue der gesamten 
Hydrobiologie. 76, 5-19. DOI: 10.1002/iroh.19910760103.

Gliwicz, Z. M. (1990). Daphnia growth at different concentrations of blue-green filaments. Archiv fur Hydrobiologie. 120, 51-65.

Green, J. (1956). Growth, size and reproduction in Daphnia (Crustacea, Cladocera). Proc. Zool. Soc. Lond. 126, 173-204. DOI: 10.1111/j.1096-3642.1956.tb00432.x.

Guo, N., Xie, P. (2006). Development of tolerance against toxic Microcystis aeruginosa in three cladocerans and the ecological implications. Environ. Poll. 143, 513-518. DOI: 10.1016/j.envpol.2005.11.044.

Gustafsson, S., Hansson, L. A. (2004). Development of tolerance against toxic cyanobacteria in Daphnia. Aquatic Ecology, 38, 37-44. DOI: 10.1023/B:AECO.0000020985.47348.5e.

Gustafsson, S., Rengefors, K., Hansson, L. A. (2005). Increased consumer fitness following transfer of toxin tolerance to offspring via maternal effects. Ecology, 86, 2561-2567. DOI: 10.1890/04-1710.

Hallegraeff, G. M. (1993). A review of harmful algal blooms and their apparent global increase. Phycologia, 32, 79-99. DOI: 10.2216/10031-8884-32-2-79.1.

Hazanato, T., Yasuno, M. (1987). Evaluation of Microcystis as food for zooplankton in an eutrophic lake. Hydrobiologia. 144, 251-259. DOI: 10.1007/BF00005559.

Hietala, J., Laurén-Määttä, C., Walls, M. (1997). Life history responses of Daphnia clones to toxic Microcystis at different food levels. J. Plankton Research, 19, 917-926. DOI: 10.1093/plankt/19.7.917.

Infante, A., Abella, S.E.B. (1985). Inhibition of Daphnia by Oscillatoria in Lake Washington. Limnology and Oceanography. 30, 1046-1052. DOI: 10.4319/lo.1985.30.5.1046.

Kotai, J. (1972). Instructions for preparation of modified nutrient solution Z8 for algae. Norwegian Institute for Water research, Oslo B-11/69, 1-5.

Lundstedt, L., Brett, M. T. (1991). Differential growth rates of three cladoceran species in response to mono- and mixed-algal cultures. Limnology and Oceanography. 36, 159-165. DOI: 10.4319/lo.1991.36.1.0159.

Lürling, M., Van der Grinten, E. (2003). Life-history characteristics of Daphnia magna exposed to dissolved microcystin-LR and to the cyanobacterium Microcystis aeruginosa with and without microcystins. Environ. Toxicol. Chem. 22, 1281-1287. DOI: 10.1002/etc.5620220614.

Matveev, V. F., Balseiro, E. G. (1990). Contrasting responses of two cladocerans in the nutritional value of nanoplankton. Freshwater Biology. 23, 197-204. DOI: 10.1111/j.1365-2427.1990.tb00265.x.

Oberhaus, L., Gelinas, M., Pinel-Alloul, B., Ghadouani, A. (2007). Grazing of two toxic Planktothrix species by Daphnia pulicaria: potential for bloom control and transfer of 
microcystins. J. Plankton Research, 29, 827-838. DOI: 0.1093/plankt/fbm062.

Ortiz-Rodriguez, R., Dao, T. S., Wiegand, C. (2012). Transgenerational effects of microcystin-LR on Daphnia magna. J. Experimental Biol. 215, 2795-2805. DOI: 10.1242/jeb.069211.

Pham, T. L., Dao, T. S., Shimizu, K., Yu, G., Do-Hong, L. C., Sugiura, N., Utsumi, M. (2015). Isolation and characterization of microcystin-producing cyanobacteria from Dau Tieng Reservoir, Vietnam. Nova Hedwigia, 101, 3-20. DOI: 10.1127/nova_hedwigia/2014/0243.

Porter, K. G., Orcutt, J. D. (1980). Nutritional adequacy, manageability, and toxicity as factor that determine the food quality of green and blue-green algae for Daphnia. In: Kerfoot, W.C.H. (ed) Evolution and ecology of zooplankton. Hanover. NH: communities University Press, 282-291.

Rorhlack, T., Christoffersen, K., Friberg-Jensen, U. (2005). Frequency of inhibitors of Daphnid trypsin in the widely distributed cyanobacterial genus Planktothrix. Environ. Microbiol, 7, 1667-1669. DOI: 10.1111/j.1462-2920.2005.00877.x.

Smith, A. D., Gilbert, J. J. (1995). Relative susceptibilities of rotifers and cladocerans to Microcystis aeruginosa. Archiv fur Hydrobiologie, 132, 309-336.

Trubetskova, I. L., Haney, J. F. (2006). Effects of differing concentrations of microcystin-producing Microcystis aeruginosa on growth, reproduction, survivorship and offspring of Daphnia magna. Arch. Hydrobiol. 167, 533-546. DOI: 10.1127/0003-9136/2006/0167-0533.

Von Elert, E. (2002). Determination of limiting polyunsaturated fatty acids in Dapnia galeata using a new method to enrich food algae with singal fatty acids. Limnology and Oceanography, 47, 1764-1773. DOI: 10.4319/lo.2002.47.6.1764.

\section{Copyright Disclaimer}

Copyright for this article is retained by the author(s), with first publication rights granted to the journal.

This is an open-access article distributed under the terms and conditions of the Creative Commons Attribution license (http://creativecommons.org/licenses/by/3.0/). 